\title{
Editorial
}

Cerebrovascular

Diseases
Cerebrovasc Dis 2016;41:101-102

DOI: $10.1159 / 000443284$
Received: November 3,2015

Accepted: December 9, 2015

Published online: January 12, 2016

\section{Elevated Blood Pressure in Acute Ischemic Stroke - Treat or Leave?}

\author{
Vijay K. Sharma \\ Division of Neurology, National University Hospital System, and Yong Loo Lin School of Medicine, National \\ University of Singapore, Singapore
}

High blood pressure (BP) levels (>140/90 mm Hg) are observed in a large proportion of acute ischemic stroke (AIS) patients during the early phase $[1,2]$. The mechanisms implicated for elevated BP include pre-existing hypertension, activation of neuro-endocrine systems, stress of hospitalisation, infarct topography, stroke subtype, stroke severity and raised intracranial pressure [3]. Despite its high prevalence, the optimal management of BP during the early phase remains a debatable issue with little consensus.

In the natural course of AIS, the BP values tend to normalize spontaneously within hours or days after AIS onset [4]. Furthermore, since the rescue of tissue at-risk remains the main goal of AIS treatment, keeping the tissue perfusion pressure above a critical level within the ischemic penumbra remains crucial. It is well known that cerebral autoregulation normally maintains perfusion over a wide range of $\mathrm{BP}$ and it is set towards higher $\mathrm{BP}$ values in chronic hypertensive individuals. During the acute phase of IS, cerebral autoregulation becomes dysfunctional and perfusion tends to be passively dependent on perfusion pressure [5]. Hence, it has been argued that BP should not be actively lowered in order to avoid any further reduction of the CBF, with the possibility of infarct extension and worsened outcome.

\section{KARGER}

(c) 2016 S. Karger AG, Basel

$1015-9770 / 16 / 0414-0101 \$ 39.50 / 0$

E-Mail karger@karger.com

www.karger.com/ced
Elevated BP is associated with higher rates of cerebral edema formation, death or dependency and hence, early intensive treatment has been advocated [4]. Interestingly, higher systolic BP was found to be associated with poor rates of recanalisation with intravenous thrombolysis (OR per $10 \mathrm{~mm} \mathrm{Hg}$ increase: $0.85,95 \%$ CI $0.74-0.98, \mathrm{p}=$ $0.022)$ [6].

It is hypothesized that intensive BP lowering during the early period may reduce the risk of symptomatic intracranial hemorrhage (SICH) after systemic thrombolysis. While elevated BP is positively associated with poor outcome, very low BP levels (systolic $<130 \mathrm{~mm} \mathrm{Hg}$ ) and large reductions in $\mathrm{BP}$ are also related to poor outcome in AIS [7]. The observed U- or J-shaped relationship of BP and outcome may be related to the overwhelming autonomic response in patients with severe AIS that often present with higher BP at presentation.

In the original National Institute of Neurological Disorders and Stroke, antihypertensive therapy was used in the placebo as well as active group. However, no conclusions could be drawn due to the small sample size [8]. Subsequent non-randomised studies indicated that elevated BP in thrombolysed AIS patients was associated with a higher likelihood of SICH. Accordingly, the Safe Implementation of Thrombolysis in Stroke-Monitoring

Dr. Vijay K. Sharma

Division of Neurology, Department of Medicine, National University Hospital Tower Block, Level 10

1E, Kent Ridge Road, Singapore 119228 (Singapore)

E-Mail drvijay@ singnet.com.sg 
Study (SITS-MOST) [9], elevated baseline systolic BP was associated with SICH (OR 1.3, 95\% CI 1.1-1.7 per $20 \mathrm{~mm}$ $\mathrm{Hg}$ ). Similarly, the Safe Implementation of Thrombolysis in Stroke-International Stroke Thrombolysis Register (SITS-ISTR) [10] showed a higher SICH rate and worse outcome in patients with elevated systolic BP. Interestingly, a U-shaped relationship was noted between systolic BP and death and dependency, with the best outcome observed in the nadir 141-150 mm Hg.

Current data indicate that $\mathrm{a} \geq 15 \mathrm{~mm} \mathrm{Hg}$ difference in systolic BP levels equates to about $15 \%$ reduction in a poor outcome after intravenous thrombolysis. However, the expert-derived recommendations are based mainly on the perceived harm from high $\mathrm{BP}$, and a definitive study for determining the optimal BP target in AIS is warranted.

The recent meta-analysis by Liu et al. [11] showed that early BP lowering after AIS did not significantly affect the risk of early and long-term death, early and long-term dependency, early and long-term death or dependency, long-term stroke recurrence, long-term myocardial infarction, and long-term vascular events. However, the included studies were limited by the late recruitment (many hours after stroke onset) and smaller BP difference between the active and control arms. Perhaps some definitive answers about the role of early intensive BP control in AIS might be obtained from the ongoing Enhanced Control of Hypertension and Thrombolysis Stroke Study (ENCHANTED) trial [12]. The ENCHANTED trial is an independent, $2 \times 2$ quasi-factorial, active-comparison, prospective, randomised, open blinded endpoint, clinical trial that is evaluating tissue plasminogen activator dose and/or BP-lowering treatment initiated during the first 6-hour. Patients are randomized to the guideline-based BP levels $(<180 / 105 \mathrm{~mm} \mathrm{Hg})$ or early intensive therapy arm (systolic target 130-140 mm Hg). In the meantime, any potential benefits of rapid BP lowering in AIS must be balanced against potential risks of worsening ischaemia from altered autoregulation and/or perfusion within the ischaemic penumbra.

\section{Disclosure Statement}

There is no financial conflict or disclosure related to this manuscript.

\section{References}

1 CAST (Chinese Acute Stroke Trial) Collaborative Group: CAST: randomised placebocontrolled trial of early aspirin use in 20,000 patients with acute ischaemic stroke. Lancet 1997;349:1641-1649.

2 International Stroke Trial Collaborative Group: The International Stroke Trial (IST): a randomised trial of aspirin, subcutaneous heparin, both, or neither among 19435 patients with acute ischaemic stroke. Lancet 1997;349:1569-1581.

3 Vemmos KN, Spengos K, Tsivgoulis G, Zakopoulos N, Manios E, Kotsis V, Daffertshofer M, Vassilopoulos D: Factors influencing acute blood pressure values in stroke subtypes. J Hum Hypertens 2004;18:253-259.

4 Willmot M, Leonardi-Bee J, Bath PM: High blood pressure in acute stroke and subsequent outcome: a systematic review. Hypertension 2004;43:18-24.

5 Powers WJ: Acute hypertension after stroke: the scientific basis for treatment decisions. Neurology 1993;43(3 pt 1):461-467.

6 Tsivgoulis G, Saqqur M, Sharma VK, Lao AY, Hill MD, Alexandrov AV: Association of pretreatment blood pressure with tissue plasmino- gen activator-induced arterial recanalization in acute ischemic stroke. Stroke 2007;38:961-966.

7 Leonardi-Bee J, Bath PM, Phillips SJ, Sandercock PA: Blood pressure and clinical outcomes in the International Stroke Trial. Stroke 2002;33:1315-1320.

8 Brott T, Lu M, Kothari R, Fagan SC, Frankel M, Grotta JC, Broderick J, Kwiatkowski T, Lewandowski C, Haley EC, Marler JR, Tilley BC: Hypertension and its treatment in the NINDS rt-PA stroke trial. Stroke 1998;29:1504-1509.

9 Wahlgren N, Ahmed N, Eriksson N, Aichner F, Bluhmki E, Dávalos A, Erilä T, Ford GA, Grond M, Hacke W, Hennerici MG, Kaste M, Köhrmann M, Larrue V, Lees KR, Machnig T, Roine RO, Toni D, Vanhooren G: Multivariable analysis of outcome predictors and adjustment of main outcome results to baseline data profile in randomized controlled trials: Safe Implementation of Thrombolysis in Stroke-Monitoring Study (SITS-MOST). Stroke 2008;39:3316-3322.

10 Ahmed N, Wahlgren N, Brainin M, Castillo J, Ford GA, Kaste M, Lees KR, Toni D: Relationship of blood pressure, antihypertensive therapy, and outcome in ischemic stroke treated with intravenous thrombolysis: retrospective analysis from Safe Implementation of Thrombolysis in Stroke-International Stroke Thrombolysis Register (SITS-ISTR). Stroke 2009;40:2442-2449.

11 Liu S, Li C, Li T, Xiong J, Zhao X: Effects of early hypertension control after ischaemic stroke on the outcome: a meta-analysis. Cerebrovasc Dis 2015;40:270-278.

12 Huang Y, Sharma VK, Robinson T, Lindley RI, Chen X, Kim JS, Lavados P, OlavarrÃa V, Arima H, Fuentes S, Nguyen HT, Lee TH, Parsons MW, Levi C, Demchuk AM, Bath PM, Broderick JP, Donnan GA, Martins S, Pontes-Neto OM, Silva F, Pandian J, Ricci S, Stapf C, Woodward M, Wang J, Chalmers J, Anderson CS: Rationale, design, and progress of the Enhanced Control of Hypertension and Thrombolysis Stroke Study (ENCHANTED) trial: an international multicenter $2 \mathrm{X} 2$ quasifactorial randomized controlled trial of lowvs. standard-dose rt-PA and early intensive vs. guideline-recommended blood pressure lowering in patients with acute ischaemic stroke eligible for thrombolysis treatment. Int J Stroke 2015;10:778-788. 